Karaseva, A., Siibak, A., \& Pruulmann-Vengerfeldt, P. (2015). Relationships between teachers ` pedagogical beliefs, subject cultures, and mediation practices of students' use of digital technology. Cyberpsychology: Journal of Psychosocial Research on Cyberspace, 9(1), article 6. doi: 10.5817/CP2015$1-6$

\title{
Relationships between teachers`pedagogical beliefs, subject cultures, and mediation practices of students' use of digital technology
}

\author{
Agnese Karaseva ${ }^{1}$, Andra Siibak ${ }^{2}$, Pille Pruulmann-Vengerfeldt ${ }^{3}$ \\ ${ }^{1}$ University of Tartu, Estonia, \& Vidzeme University of Applied Sciences, Latvia \\ 2 Institute of Social Sciences, University of Tartu, Estonia \\ ${ }^{3}$ Institute of Social Sciences, University of Tartu, \& Estonian National Museum, Estonia
}

\begin{abstract}
Drawing on the data from 26 interviews with different subject teachers in two countries, Estonia and Latvia, this study aimed to reveal how pedagogical beliefs and subject cultures shape the ways primary and secondary school teachers mediate students' use of digital technology. Teachers are acknowledged to be important socializing agents, affecting young people's experiences with digital technology, but it is still unclear how the mediation practices of teachers are related to such intrinsic factors as teachers ' beliefs about the nature of learning, nature of technology, self-efficacy beliefs, and subject cultures. Our study indicates that teachers mainly act as guides or coaches to help students make sense of the various opportunities that digital technology provide. Teachers also use a variety of restrictions related to technology use according to their dominant pedagogical beliefs and subject domains. These two roles are not mutually exclusive, combining according to what teachers believe will best support learning. A small group of teachers in our sample also strive to broaden students' understanding and adopt new skills for using technology in innovative ways. Implications for teacher training and peer-to-peer learning are discussed based on our findings.
\end{abstract}

Keywords: teachers as mediating agents, teachers ' beliefs, subject cultures, digital technology, teachers' practices

\section{Introduction}

Many parents expect their children to acquire primary digital literacy and online skills at school (Livingstone \& Haddon, 2012). This automatically sets the question as to whether teachers are ready to respond to this expectation and mediate children through the various opportunities and guide them through the possible risks that digital tools and environments provide. In this article, we make use of the data gathered from 26 semi-structured interviews with in-service teachers from Estonia and Latvia to explore the links between teachers ' mediation practices and their pedagogic beliefs about information and communication technology (ICT) as well as their own perceived technology competence.

The concept of mediation, which has its roots in the TV viewing studies, where it was mainly related to different strategies of "supervision and guidance" (Warren, 2003, p. 395) as carried out by parents, has more recently moved away from the traditional "protectionist paradigm" (Mendoza, 2009, p. 33) and emphasizes the role of other mediation agents, namely, teachers and peers. 
Parents have been usually addressed as the most influential mediators in shaping young children 's media experiences, drawing on the assumption that "children consume most media at home" (Mendoza, 2009, p. 28). At the same time, with the advent of new technologies in schools worldwide, the importance of understanding teachers affect on young children's technology use is growing (De Haan \& Livingstone, 2009). Although there is a well established research tradition on scaffolding as part of teachers ' everyday practice in educational research which draws on the Vygotskyan notion of mediated learning [i.e. interactions between learner and teacher which bring the child to learning situations that are more complex than "those that they [children] can master themselves" (Kozulin, 2003, p. 19)], we believe that there are three reasons why teachers" interventions should be analyzed from the perspective of mediation. First, scaffolding does not capture fully the complexity of the realities of teachers who find themselves being held responsible for the development of students' transversal skills, like digital competence and information literacy (European Commission, 2014), collaboration, problem solving skills, and creativity (Voogt \& Pelgrum, 2005). Second, exclusion of teachers' voices from the growing discussion about mediation practices will lead to losing something in our understanding regarding the three groups of important mediating agents - parents, teachers, and peers - with different social relationships and distinct roles in influencing children's online experiences (Kalmus, von Feilitzen, \& Siibak, 2012). Third, this approach helps to raise questions related to teacher media literacy development and discusses implications for the student, teacher, and in-service teacher training (UNESCO, 2011).

Regardless of the growing importance of the topic, the knowledge of teachers ' mediation practices is still rather limited. In fact, only a few studies (e.g., Hasebrink et al., 2009; Kalmus et al., 2012; Livingstone \& Bober, 2004; Zhao, Lum, Wang, \& Huang, 2010) have paid attention to teachers ' mediation practices, considering them as the primary sources for learning about internet literacy. To our best knowledge, teacher mediation practices have mainly been studied by applying quantitative measures. There is also a limited amount of research about teachers ' roles as mediators conducted in several countries simultaneously. The EU Kids Online survey in 2010 collected data from 25 countries, and the mediation practices of teachers were analysed through the responses of children and their parents (Livingstone, Haddon, Görzig, \& Ólafsson, 2011). The purpose of our study is to address the gap in the literature on teachers' medication practices.

As argued by Cox (2008), substantial previous research into teachers' use of ICT indicate that teachers ' practices depend heavily on teachers' beliefs and theories of teaching (Ertmer \& Ottenbreit-Leftwich, 2010), and of the culture within which the teacher operates (Hammond, Reynolds, \& Ingram, 2011; John, 2005). Hence, in the present paper, we will examine teachers' practices concerning technology use from the perspective of subject cultures (Goodson \& Mangan, 1995). Furthermore, we expect that pedagogic beliefs and teachers ' positions as expert or novice technology users to be important determinants of their mediation practices. In our approach, we follow Nikken and Jansz (2011) who propose that attitudes and perceived competence shape the ecology of intervention in which the adult mediator operates. We aim to answer the following research questions:

RQ1: How do teachers ' pedagogical beliefs affect their mediation practices of students ' use of digital technology?

RQ2: How do mediation practices of teachers relate to the subject cultures and their perceived ICT self-efficacy?

RQ3: What kind of practices do different subject teachers use in order to mediate students' use of digital technology?

\section{Theoretical and Empirical Background of the Study}

\section{Aspects Affecting Teachers' Beliefs about the Use of ICT}

It has been acknowledged that teachers ' practices (Pajares, 1992) and usage of different technological tools (Ertmer, 2005) are shaped by a variety of beliefs that teachers hold. One's beliefs about the role of technology as a teaching tool, the value of technology for student learning, and one's own knowledge and skills intersect with teachers' established pedagogical beliefs. These beliefs are established during early teaching experiences and they are deeply personal and hard to affect by persuasion. As beliefs influence the processing of new information (Pajares, 1992), attitudes toward new tools, like ICTs, are strongly challenged when existing beliefs do not coincide with those underlying the technology (Cox et al., 2004). In fact, regarding the advent of ICTs, beliefs have been identified as the "second order barrier" to technology integration as being opposite to the "first order barriers," which are extrinsic factors including 
the lack of resources, access, and technical support (Ertmer, 2005). The first order barriers have been generally overcome, making the second order barriers the final frontier to technology integration.

Teachers' beliefs about a variety of teaching aspects may affect their use of digital technologies in class and their roles as mediators of students' ICT skills. One teaching aspect that is crucial to mention are teachers' beliefs about the nature of learning and teaching. In educational research, teachers ' beliefs and practices have often been addressed from the constructivist/instructionist perspective. It is self-evident that more intensive computer use in class is associated with the development of student-centred and constructivist approaches (Kozma, 2003). Still, some researchers have strongly questioned this link arguing that technology itself does not embody a student-centred instructional paradigm (Niederhauser \& Stoddart, 2001). In reality, teachers ' choices of technology and their practices fall somewhere "between" the opposite ends. Research reveals that teachers' decisions about technology in the classroom depend on their perception on the affordances of the particular tool and the learning goal (Lim \& Chai, 2008). Hence, teachers ' beliefs can be described as enacted or situational, and even holding highly student-centred beliefs, teacher can rely on teacher-centred approaches. Teachers' choices can derive from a complex set of factors, including availability of tools, learning goals of the particular lesson, assessment system, and time pressures for preparing students to participate in examinations.

Watson (2006) argues that teachers' beliefs regarding integration of technology are based on their assumptions about whether the technology will support the achievement of the instructional goals. Following the same line of reasoning, Cox et al. (2004) examined teachers' belief about the value of technology, focusing on the distinction between perception of the tool as a "servant" to reinforce the existing practices or as a "partner" for changing the ways the interactions in the classroom happen. The findings of some studies illustrate teachers' beliefs that technology is good only as a reward tool (Palak \& Walls, 2009), a tool that best suits learning in the early years and primary classes (Hammond et al., 2011), or a tool which brings "fun" to the classes (Zhao, 2004). Other research reveals that teachers worry about technology use as a time-wasting activity and a production of "neat nonsense" (Reynolds, Treharne, \& Tripp, 2003), or as "edutainment" with a consequent loss of learning (John \& Baggott la Velle, 2004). Research suggests that these beliefs are dependent upon teachers' self-efficacy about their technology competence (Bandura, 1997). Studies indicate that teachers' beliefs and their use of technologies in class are dependent on the subject and school cultures that teachers belong to (Ertmer, 2005; Hammond et al., 2011; Karaseva, Pruulmann-Vengerfeldt, \& Siibak, 2013).

Subject cultures which are expressed through classroom organization and pedagogical styles, should be understood as a "general set of institutionalized practices and expectations which has grown up around a particular school subject, and which shapes the definition of that subject as both a distinct area of study and as a social construct" (Goodson \& Mangan, 1995, p. 615). In other words, subject knowledge is a form of collective knowledge, and teachers collectively form an understanding where the subject boundaries lie (Ellis, 2007).

Studies have found that teachers' beliefs about class technology use differs among science and humanities teachers. One reason for this difference might be the different ways prospective teachers are introduced to the affordances of ICT. For instance, a diversity in focus on technology has been reported to exist in teachers' initial training as teachers of the humanities or the sciences (Hammond et al., 2011). Another aspect is the perceived subject nature and the question as to how well the new technology fits with existing subject practices and content (Selwyn, 1999). For example, John and Baggott la Velle (2004) argue that science and mathematics teachers are more willing to integrate technology in their teaching, because these subjects are perceived as more linked to technology. English teachers, on the contrary, are more anxious about "losing the core features and values" of their subject, classroom discussion, and use of printed text (Hennessy et al., 2005).

\section{The Role of Teachers as Mediating Agents}

Previous research indicates that due to the different social relationships between the child and the mediator, and considerable differences between the characteristics of the classroom and home environments, the frameworks conceptualizing parental mediation strategies, cannot be directly applied to studying teachers' mediation (Kozulin, 2003). Although different authors (e.g., Kalmus et al., 2012; Inan, Lowther, Ross, \& Strahl, 2010) have proposed a variety of possible roles that teachers could have, there is no universal framework which could be used in the context of teacher mediation. In this article, we draw upon the work of Kalmus (2013), who proposed a framework which considers the potential roles of three main mediating agents - parents, teachers, and peers. According to Kalmus, these mediating agents can play the following four roles. 
1) Gatekeepers (or filters) select and decide what content children will access, what activities they will take, and what activities, platforms, and topics children will be restricted from.

2) Guides or interpreters (or signposts) help children through the "jungle" of the Internet and help to make sense of the online experience, paying attention to what seems to be puzzling or difficult to cope with.

3) "Windows" extend children 's vision of the online world, new media, and the scope of online opportunities.

4) Consolers or trustees are there for children to turn to after having experienced something harmful online. Their role is related to retroactive mediation.

Teachers' roles as guides or facilitators have been acknowledged in empirical findings. For instance, Kalmus et al. (2012) revealed that teachers ' mediation is positively correlated with students ' digital and safety skills. Nevertheless, finding a right balance among restrictions, safety, and digital literacy guidance is a crucial matter as putting too heavy restrictions on web sites could prevent students from exploring additional opportunities (Wishart, 2004).

The findings of Zhao et al. (2010) also suggest that teacher support has a small but significant influence on high school students' curiosity about the Internet, but only a weak influence on the intrinsic motivation to use of the Internet. The latter finding is also supported by the results of Kalmus et al. (2012) who found that teacher mediation was the weakest predictor for taking up the opportunity of online content creation. Hence, empirical studies suggest that the role of teachers as "windows" of children's computer and Internet use is rather insignificant.

\section{Countries`Background}

We believe that there are several reasons why Estonia and Latvia serve as interesting cases for studying the mediation practices of teachers.

Firstly, children in both countries regard their teachers to be quite active in mediating children's internet use. According to the EU Kids Online findings, $72 \%$ of Estonian children report that their teachers have used active mediation and $15 \%$ believed that their teachers used other methods for guiding their internet usage (Kalmus et al., 2012). Latvian teachers, however, have taken the role of informers when it comes to children's internet use, with $84 \%$ of children declaring that their teachers performed at least one of the eight internet monitoring strategies (Brikse \& Spurava, 2014).

Secondly, children in both countries tend to be very confident about their own knowledge and computer skills. In Latvia, $49 \%$ of $11-16$ year olds in one study agreed with the statement: "I know more about the Internet than my parents" (Brikse \& Spurava, 2014). According to the EU Kids Online findings, Estonian children were reported as the most skilful youths in Europe regarding their technology skills (Kalmus et al., 2013).

Thirdly, both countries strive to make digital skills an integral part of every subject curriculum (Mägi, 2006; Kangro \& Kangro, 2004). Regardless of the fact that in both countries the national curriculum defines digital competences among other core competences (Latvian Ministry of Education and Science, 2013; Estonian Ministry of Education and Research, 2011), there are no formal guidelines on how subject teachers should deal with ICTs' and digital skills ' promotion in their teaching (Grivins, 2012). In both countries, general education is provided through municipality-owned schools, and the education is organized in two levels: basic level (grades 1-9) and upper-secondary level (grades $10-12$ ).

Considering the above, our aim was to explore the links between teachers ' mediation practices and their pedagogic beliefs about ICT as well as their own perceived technology competence.

\section{Methods}

Our data derive from two separate datasets. The first was gathered during autumn 2012 in Estonia, and the second one in spring 2013 in Latvia. Although conducted separately, these two data sets covered overlapping blocks of themes, and therefore it is possible to analyse the overlapping themes. In addition, we analyse the overlapping sections which focused on teachers 'opinions about their role as mediators, their instructional and mediation practices, and the beliefs that underlie these practices. Since there is a dearth of studies on teachers ' mediation, we aimed only at giving an initial broader overview of the teachers ' mediation practices, not making any cross-national claims or generalizing our findings, rather 
focusing on the micro level of mediation as an "embedded practice" carried out by teachers, as suggested by Kalmus (2013). We believe the chosen approach to be suitable for giving a general overview and outlining some themes for future research in this realm.

\section{Participants}

Our sample consists of 26 participants, of which 10 subject teachers come from five different schools around Estonia and 16 subject teachers from a middle-sized school ( 500 students) in a regional town in Latvia. Participants of our study teach at different levels of basic and secondary education (see Table 1).

Table 1. Overview of the Sample.

\begin{tabular}{lccccc}
\hline Subject & Total & \multicolumn{2}{c}{ Estonia } & \multicolumn{2}{c}{ Latvia } \\
& & $\begin{array}{c}\text { Number of } \\
\text { participants }\end{array}$ & $\begin{array}{l}\text { Grades } \\
\text { taught }\end{array}$ & $\begin{array}{c}\text { Number of } \\
\text { participants }\end{array}$ & $\begin{array}{c}\text { Grades } \\
\text { taught }\end{array}$ \\
\hline $\begin{array}{l}\text { Sciences teachers (math, physics, } \\
\text { chemistry, biology, geography) }\end{array}$ & 12 & 5 & $7-9$ & 7 & $7-12$ \\
$\begin{array}{l}\text { Humanities teachers (history, music, } \\
\text { foreign languages, mother tongue) }\end{array}$ & 14 & 5 & $7-9$ & 9 & $7-12$ \\
\hline
\end{tabular}

All the teachers forming our sample had passed ICT-related training courses and claimed to use computers and other ICT tools for teaching and administrative purposes. In the process of selecting participants, our aim was to capture a wide variety of practices related to educational ICT tools. Hence, in the context of this paper the usage of various input sources (e.g. tablet, PC, document camera), output sources (e.g., projector, interactive whiteboard) and other technological tools (e.g. digital camera, digital recorder, etc) were understood as the usage of ICTs for in-class educational purposes. All the teachers in our sample had access to computer labs, could use personal computers and data projectors, and in some cases tablets, interactive whiteboards, document cameras, and digital recorders.

In the Latvian school, the vice-headmaster responsible for ICT development was asked to suggest teachers who teach the same subject (e.g., English as foreign language), but represent different levels of ICT integration in their teaching. The final Latvian sample consisted of female teachers who had 10 to 30 years of work experience.

For choosing participating schools in Estonia, one of the criteria was involvement in training programs and activities organized by the Tiger Leap Foundation. We differentiated between schools which had been quite active in taking part in various ICT related initiatives organized by the Tiger Leap Foundation, schools that had taken part in some of those activities, and schools whose teachers had no connection to ICT-related training courses and activities. Schools were contacted by e-mail and those which responded positively to our request were asked to suggest one teacher of humanities and one of sciences from their school who were accustomed to using ICTs in everyday teaching, and would be willing to participate in the study. The final Estonian sample comprised of nine females and one male teacher. All the teachers in the sample had at least three years of teaching experience; however, some of them had more than 20 years of experience.

We are well aware that the chosen approach for selecting participants for the study in each country was different. However, our aim was not to compare the two countries, but rather to grasp various mediation practices among different subject teachers. Being aware of the limitation, we excluded the aspect of influences from the school culture from our analysis. In fact, the interviews with the Estonian sample focused more on individual teachers. The general overview on diversity of teachers' practices was ensured by the fact that teachers came from different schools located in different places in the country. Latvian teachers, however, were invited to describe their own practice in order to reflect on the broader picture of the diversity of teachers' practices of employing ICTs in their school and in their subject. 


\section{Data Collection}

Individual semi-structured interviews were conducted, all of which were audio-taped and later transcribed. The interviews lasted for about one hour and focused on various topics. In both countries, the interview protocols covered the teachers' self-assessments of their computer knowledge and skills, as well as their preferred ways of using technology in teaching. We also asked them to reflect on how the work and role of a teacher has changed after introducing ICTs in education, and we encouraged them to reflect upon their own role in promoting students' digital competences.

Although the interviews with Estonian teachers were carried out six months prior the ones in Latvia, we do not believe this time gap has significant effects on our findings. We rely on the argument made by Kagan (1992) that teachers' beliefs reflect a compatible teaching approach which tends to be consistent over time and with different types of classes and different types of students.

\section{Data Analysis}

We started the analysis with hierarchical coding as suggested by Straus and Corbin (1998). First we did the initial open coding to split our interview material in smaller units of analysis. Then we continued with focused coding and close reading of the interview material, specifically looking for themes and patterns in teachers ' speech regarding their opinions about their role as mediators, their mediation practices, and their pedagogic beliefs that are linked to these practices.

The data was analysed in two separate groups: interviews with science teachers (i.e., math, chemistry, physics, and geography), and humanities teachers (i.e., languages, music, civic, history). At the final stage of data coding, we classified them under the categories of teachers ' roles as mediators.

Estonian data was coded by both Estonian authors. They did the initial data coding separately from each other, and then compared the codes and discussed the labeling of data several times before full agreement was reached. Due to the language difference, the Latvian data was first coded by the main author of the article, and after the selected units from interviews were translated to English, the data was discussed over several meetings with one of the Estonian authors. Only after the researchers had reached full agreement the labeling of the Latvian data was done. Through the procedure described above we ensured the reliability of the data.

\section{Results}

In this section, we will summarize our main findings, revealing the complex picture of science and humanities teachers' pedagogical beliefs regarding educational use of technology, their beliefs about the nature of learning, and their roles as mediators.

\section{Teachers Pedagogical Beliefs Related to their Mediation Practices}

\section{The nature of technology}

Our analysis suggests that most science and humanities teachers from our sample believed that ICTs were valuable tools to support existing teaching practices. Teachers sharing this belief showed rather positive attitude toward technology integration, arguing that technology is good for demonstration and visualization and also helps to explain complicated topics.

"Yes, this [ICT] does support. Showing different films or things like that. When in old times you had to dust off the film projector, rewind the film to the beginning and then show it, and then again if you wanted to repeat something, then this is much more convenient now."

(Teacher of physics, Estonia)

Teachers of humanities, in general, and language teachers, in particular, valued technology as a tool for drill and practice. Our analysis indicated that humanities teachers saw the advantage in the time that they could save on correcting students' work, because the system gives instant feedback and automatically marks the mistakes.

"... it [ICT] is very good, brings variety, I like. As much as I can, I use. It would be great when everyone would have laptops, then we could do more online exercises, like at the moment, we 
do it so that I demonstrate on the board and students watch, but we could do it together and see how it works out."

(Teacher of German language, Estonia)

Language teachers in both countries also reported using technology for storing learning materials, which they had collected for their own use and for giving to students so that they can practice individually during the lessons and also at home. Science teachers valued the ready-made materials available on special online platforms, which contain lesson plans, worksheets, and other learning materials suitable for their purposes.

At the same time, teachers in both countries were concerned about becoming too dependent on technology as a "servant." Teachers stressed the need to be prepared to also work without technology in case the Internet connection gets disrupted, there is unexpected shutdown of the computer, or the digital material suddenly is not accessible. Hence, traditional teaching in combination with ICTs and studentcentred approaches were seen as ideal.

In fact, only a few teachers from the sciences as well as humanities saw the transformative potential of technology and promoted development of students' skills for more diverse use of different technology. Technology was perceived to be a "partner" usually by teachers with high technology confidence and selfefficacy. In most cases, such a belief was also linked to the constructivist approach, which viewed students as partners in the process of learning. For instance, one language teacher from Latvia showed students how to produce small videos related to language learning.

"Children are very creative, I think. At the moment everybody likes making videos, before presentations were on the top, also posters. I like to learn many new things myself, therefore, I care that students learn, too."

(Language teacher, Lativa)

A small group of teachers who also happened to have lowest perceived self-efficacy compared to the rest of the sample, treated technology with suspicion and saw it as potentially treacherous.

"I am very sceptical about ICTs, don 't know how to use it in the class. It is for entertainment only, I don't see the educational value. Really, why waste time on watching movies, let's say, about England? Students have no interest, and many of them have been abroad anyway. They [students] travel often."

(Teacher of English language, Latvia)

These teachers were also afraid of the fact that playfulness which may come from using ICT may actually distract the students from serious learning. For example, some language teachers from both countries expressed worries about the potential distraction of the relationships and the role of the teacher from more extensive use of technology. The latter concern is also one of the reasons why teachers belonging to this third group claimed to be using technology occasionally, mainly for administrative purposes. When talking about technology in the classroom, they described ICTs as "unavoidable," stressing the normative nature of technology integration in education.

\section{Teachers`Beliefs about the Nature of Learning}

Differences between subject cultures became evident when analysing teachers' beliefs about the nature of learning. Compared to the humanities' teachers who saw the goal of learning to be striving for good grades, science teachers emphasised the need to educate the students about "how things work." In fact, they believed that technology is helping them to achieve this aim either by providing the additional means for demonstrating and explaining some processes better or by letting students search and explore things by themselves. For example, one teacher of geography noted that when searching for information related to her subject, students also become more skilled and efficient users of the Internet. Some science teachers in the Estonian sample, however, clearly distinguished between "classic knowledge," what students learn from books and which should not be taught with technology, and the "other knowledge" that can be found from online resources.

"I think that classic knowledge, those should be given without computer... The minus [of ICTs] is that students will start taking things so easy. That they know ahh, I will check it out when the test comes and during the lecture, I will play tetris or don't attend the class at all."

(Teacher of physics, Estonia) 
Latvian language teachers, however, believed very strongly in learning as an active process that happens in close interaction between students and the teacher. In their views, technology could be of little help in that respect.

\begin{abstract}
"I accept only hand-written essays. Their [students] handwriting gets better, their thinking becomes more organized. How else will they learn the skill to organize a piece of text? With ICT, students stop developing, they lose their creative skills. You see what happens with professional writers? They go back to typing machines nowadays."

(Teacher of Latvian as mother tongue, Latvia)
\end{abstract}

Furthermore, some teachers of humanities and a few of the science teachers in the Latvian sample expressed a belief that students with lower subject knowledge will not benefit from working with technology, because serious learning, as one of the teachers of mathematics said, "Happens when students ' mind work, and not their fingers." Science teachers agreeing with this statement claimed to use computers only rarely with low performing student groups as they believed that computers are too big of a distraction. Language teachers holding a similar view allowed only the best performing students to do exercises online, whereas the rest of the group needed to do them on paper and under the supervision of a teacher.

\title{
Self-Efficacy Beliefs and Mediation
}

The only cross-national comparison that we make in this study is related to teachers ' perceived technological self-efficacy. Estonian teachers, who worked with younger students (grades 7-9), felt more confident about their technology skills compared to their Latvian colleagues working with older students (grades 7-12). This could also be the reason why Estonian teachers talked more about how they perform their role as mediators. The Latvian teachers working with older students sometimes tended to be impressed by the technical abilities of their students and therefore they neglected their own potential of contributing to the enhancement of students' skills. In fact, some of them evaluated their role as mediators to be marginal or non-existent.

At the same time, the teachers in the Estonian sample noted that there was a diversity of digital skills among different groups of students and hence their own self-efficacy was dependent on the specific group of students one needed to teach.

"This [mediating role in advancing student's ICT capabilities] differs. There are classes which are very strong and there I feel that I need to hide how little I know, but there are classes which are very weak."

(Teacher of social sciences, Estonia)

Analysis of our data also revealed two examples of reverse mentoring (Peterson, 2012) where teachers with low perceived technology competence asked the students to carry out specific tasks on their behalf. Such practice was expressed by a music teacher in Latvia and a social science teacher in Estonia. In both cases, teachers admitted to not being ashamed of such a practice.

"I have long understood that some people are far superior [to my ICT skills], like some students, so you just make them work for you. They will teach how to do, what to do, and what other possibilities there are. I have done it and I am not ashamed to admit that they are smarter than I am, this is normal. I think this is all as it should be, yes..."

(Teacher of social sciences, Estonia)

In comparison to the Estonian teachers, Latvian teachers in our sample did not use students as a reference group, but talked more about their technology self-efficacy in comparison to other teachers of the same subject. One of the aspects that teachers emphasized was the relationship between technology self-efficacy and perceived low level of foreign language skills of science teachers. In their opinion, the lack of knowledge on these fields prevented science teachers from working with many tools and resources.

However, there was no relationship between teachers' experience at school and their self-efficacy. Teachers who reported high self-perceived ICT competence were found among the ones with fewer years of experience and also among the veteran teachers who had worked at school for 30 years. 


\section{Teachers` Perceptions of their Role as Mediators}

Analysis of our data indicates that teachers perform three of the four roles: gatekeepers, guides or interpreters, and "windows,"- proposed by Kalmus (2013) (see Table 2).

Table 2. Overview of Teachers ' Roles, Strategies and Activities of Mediation.

\begin{tabular}{|c|c|c|}
\hline Mediator role* & Mediation strategy** & Teachers' activities \\
\hline Gatekeepers & $\begin{array}{l}\text { Social and technical restrictions, } \\
\text { monitoring, setting rules }\end{array}$ & $\begin{array}{l}\text { Rely on supervised internet access } \\
\text { Try to protect students from seeing potentially } \\
\text { harmful content online } \\
\text { Limit students`opportunities to use ICT based on } \\
\text { teachers` perceptions about students`ICT } \\
\text { competences } \\
\text { Require homework to be handwritten }\end{array}$ \\
\hline Guides coaches & $\begin{array}{l}\text { Active mediation, co-use, } \\
\text { interpretive mediation }\end{array}$ & $\begin{array}{l}\text { Teach about netiquette } \\
\text { Teach to do searches online } \\
\text { Teach how to use different software/ hardware } \\
\text { Aim to develop students` critical thinking skills } \\
\text { Teach about ethics online, e.g., referencing sources } \\
\text { Involved in discussions with students about digital } \\
\text { opportunities } \\
\text { Do searches online together, discuss the results }\end{array}$ \\
\hline "Windows" & Active mediation, co-use & $\begin{array}{l}\text { Teach how to produce videos } \\
\text { Teach how to blog } \\
\text { Teach how to use ICT for collaboration, sharing, } \\
\text { project work }\end{array}$ \\
\hline
\end{tabular}

Both Estonian and Latvian science and humanities teachers acknowledged that they use restrictive mediation, i.e. they take up a role of a gatekeeper. In doing so, they combined both technical as well as social restrictions. Technical restrictions were exercised by letting the students work mainly with the "right resources" - specific websites and online databases, which the teacher pre-selected, evaluated, and accepted as being of educational value. Teachers of foreign languages (English and Russian) reported their practice of keeping lists of online addresses which they gave to students for working during lessons and also for doing homework. They explained that, first of all, students would not be able to find these materials by themselves, thereby pointing to the limited search skills of students, and second admitting that generic online resources often contain information which is not appropriate for students 'eyes. Social restrictions, however, were exercised by letting the students hand in only hand written homework.

There were also both science and humanities teachers from each country belonging to the group of those individuals who acknowledged ones role as guides or coaches. These teachers used active and interpretative mediation to support and help students navigate in the "jungle" of online resources. These teachers saw their role as mediators being crucial in three main realms, including teaching students how to do information searches online, to develop students' abilities to evaluate the quality of information and its relevance to the topic, and to help students consider the reliability of the source. For instance, one physics teacher in the Latvian sample, reported that she often asked her students to search for information online so as to later discuss the findings in class. Through this, she argued, students learn the topic better and also improved their skills of treating online resources critically. Teachers taking up the role of a "guide" emphasised the importance of critical thinking skills in the context of machine translation tools like Google Translate, which according to them was far from being error-free.

Teachers were also ready to take the role as guides as far as correct referencing and formatting matters were concerned. They described how they had advised students how to apply different formats and layouts in their homeworks, such as in writing essays and creating presentations. Some teachers from the 
Estonian sample also talked about netiquette. For example, they have taught students how to compose an email that would not irritate or offend the recipient.

A small group of teachers from our sample performed the role of "windows" by expanding students ' use of diverse ICTs for creative self-expression, production, and sharing of original content. For instance, one Latvian biology teacher and one Latvian language teacher used active mediation and co-use strategies when helping students to increase their knowledge and skills of blogging and video production.

However, our data analysis did not reveal any teacher practices that would correspond to the fourth possible role of teachers (i.e., counselors or trustees) proposed by Kalmus (2013).

\section{Discussion}

In this article, teachers beliefs and classroom cultures were presented in relation to their roles as mediators, intervening in students ' use of ICT. Due to the relatively small sample, the findings are not readily generalizable, but we believe they provide some implications for teaching practices, especially those practices related to the professional development of teachers.

Our findings suggest that compared to science teachers, teachers of humanities showed the biggest variety in their attitudes towards technology, their teaching approaches, and their perceived technology competence. Among humanities teachers, we found a small group of teachers who valued the transformative potential of technology. They expressed concerns about students ' abilities to apply technology for meaningful learning, self-expression, creative content production, and other tasks considered to be crucial for modern learners (European Commission, 2014). Most of the humanities ` teachers, regardless of having positive attitude toward ICTs, employed technology in ways which fell at the instructionist end of the constructivist-instructional continuum (Ertmer et al., 2000). Thus, our findings seem to support the argument of Niederhauser and Stoddart (2001) that extensive use of different tools does not automatically lead to more student-centered teaching approaches. Lim and Chai (2008) argued that teachers' practices depend on their perceptions of the learning goals. A strongly argued idea among humanities teachers in our sample was that learning, especially among older students, means striving for good grades. Technology, according to this belief, had its role as a useful tool for drill and practice, or was applied as a reward (Palak \& Walls, 2009).

Among humanities teachers, we also found that the biggest variety of perceived self-efficacy from individuals with very low perceived technology competence. These individuals strictly limited ICT usage. They strongly questioned the need for technology in education. We found this trend mainly among language teachers who showed anxiety over losing the "core" values of the subject, choosing to have students write by hand and engage in classroom discussion (Hennessy et al., 2005).

In addition, we found examples of reverse-mentoring (Peterson, 2012). These teachers claimed to benefit from the assistance of their students for troubleshooting technology problems or for learning new ways to use ICTs. Reverse-mentoring has proved to be an effective alternative for teachers with lower levels of digital skills to overcome some of the difficulties they face when using technology (Ertmer et al., 2012).

Compared to the teachers of humanities, science teachers in our sample seemed to be more positive in their opinions about the value of ICTs in education. They applied a mix of open-ended and practice tools, but they seemed to value the student-led inquiry more than teachers of humanities. Instead of striving for good grades, they valued the enhancement of students' understanding about different processes, namely, understanding about "how things work." There were no individuals with low perceived computer self-efficacy among the science teachers, but we found, like among humanities teachers, some teachers with high self-efficacy and also orientation toward innovation, enabled the transformative potential of technology. However, this group was a small one. Our analysis indicates that despite the positive attitudes toward technology in general, science teachers also saw the role of ICT to be mainly be as a "servant," which helps to sustain existing teaching practices (Cox et al., 2004). A common feature among some science and humanities teachers was the belief that technology cannot support the learning of students whose knowledge of the topic is not adequate. Such an idea was linked to their belief that ICTs somehow prevented students from deep and meaningful learning (Reynolds et al., 2003).

Our results suggest that science teachers felt more confident with technology than teachers of humanities. One possible reason for such a difference in perceived self-efficacy could lie in the fact that humanities teachers work with generic resources that are not specifically designed for teaching purposes whereas science teachers basically relied on subject specific applications and interfaces. Hence, our 
findings coincide with the results of John (2005) who found that science teachers tended to work with technology that was specifically developed for educational reasons and designed to serve the teachers ' needs, while humanities teachers felt additional burden for having to depend on generic resources.

We believe that by trying to capture teachers' beliefs about technology use and learning, and the application of ICTs within their distinct subject cultures, we are able to develop a better understanding of the mediation practices of teachers. Our data analysis revealed some distinct features related to teachers' roles as social mediators (Kalmus, 2013). Gatekeeping as a mediation practice was not exclusively related to the instructivist approach to learning. Similar to the findings of Wishart (2004), "gatekeepers" relied on supervised Internet access and students mainly visited websites which were recommended by teachers. Gatekeeping was also apparent when asking teachers about the ways students were allowed to prepare assignments. We cannot say that this role was particularly related to teachers' self-efficacy, though. Gatekeeping as an occasional practice in our sample seemed to happen in the classrooms of the most technologically advanced teachers with dominant constructivist beliefs. These teachers spoke about their enacted practices (Lim \& Chai, 2008), which they applied according to the learning goal or the current availability of particular tools. Some mentioned the students ' mood on a particular day as an aspect used for considering the utilization of resources and teaching methods. Our data revealed that teachers of humanities tended to perform the role of gatekeepers more often than science teachers.

Our study revealed a variety of practices that teachers performed as guides or coaches (Inan et al., 2010). The role of a guide was related to teachers' medium or high self-efficacy, but it was not related to either constructivist or instructivist teaching approaches. Regarding the roles of gatekeepers and guides/coaches, our data indicated that they were not mutually exclusive, rather they were performed in an integrated way. Which role dominates in every particular situation seems to be related to teachers' understanding about what will best facilitate achievement of the learning goal and suit learners ' and teachers` needs (Lim \& Chai, 2008; Zhao, 2004).

The role of "windows" in our sample was performed by a few science and humanities teachers with high self-efficacy beliefs and a teaching style which corresponded to the constructivist approach. Teachers taking the role of "windows" seemed to care about students' transferable skills to be able to use technology in creative and innovative ways in different aspects of life and learning (European Commission, 2014). Our analysis did not show evidence that teachers perform the role of consolers or trustees (Kalmus, 2013). Perhaps employment of other data collection methods, e.g., classroom observations, could enable us to capture this role in teachers ' practices.

Our analysis indicates that teachers are the most powerful mediators of digital technology use in the school setting. Their choices of learning approaches and tools can enhance or limit students understanding about the use of ICTs. As our study revealed, many teachers use ICT in innovative and creative ways, integrating subject learning and promotion of digital literacy. Yet teachers should become more aware of their role as mediators and seek ways to make media and digital literacy promotion a natural part of subject teaching. Furthermore, we believe that teachers' self-efficacy is one of the first issues that needs to be tackled to strengthen their role as mediators. In fact, we argue that teachers should develop their own media literacy to help students to interpret media messages, and apply media for self expression and participation (UNESCO, 2011). The latter could be achieved through improved teacher education and also in-service teacher training.

Although teachers' beliefs are very resistant to change (Pajares, 1992), our findings suggest that professional development based on the subject cultures could help teachers overcome fears about their self-efficacy or beliefs about limited affordances of technologies in education. Many of the teachers in our sample reported to being in contact with other teachers from the same subject domain and occasionally exchanging learning materials. Intensifying the peer contacts and learning among teachers could be a way of triggering changes in the existing practices. Thus, we believe peer-to-peer learning to be a promising field for future studies on teachers' mediation practices. Perhaps action research approaches could contribute to helping teachers overcome the barriers that are related to their use of ICTs and their abilities to mediate students' ICT usage.

\section{Acknowledgement}

The authors are grateful for the support of the project PUT44 financed by Estonian Research Council. 


\section{References}

Bandura, A. (1997). Self-efficacy: The exercise of control. New York: W. H. Freeman \& Co.

Brikse, I., \& Spurava, G. (2014). Kids online - safety and risks: full findings from children survey of 9- to 16-year-olds in Latvia. Retrieved from: http://eprints.Ise.ac.uk/60574/

Cox, M., Webb, M., Abbott, C., Blankely, B., Beauchamp, T., \& Rhodes, V. (2004). ICT and pedagogy. Becta Report. Retrieved from http://archive.teachfind.com/becta/research.becta.org.uk/uploaddir/downloads/page_documents/research/ict_pedagogy04.pdf

Cox, M. J. (2008). Researching IT in education. In J. Voogt \& J. Knezek (Eds.), International handbook of information technology in primary and secondary education, Section 10: Researching IT in education (pp. 965-982). New York: Springer.

De Haan, J., \& Livingstone, S. (2009). Policy and research recommendations. London: EU Kids Online.

Ellis, V. (2007). Taking subject knowledge seriously: From professional knowledge recipes to complex conceptualizations of teacher development. The Curriculum Journal, 18, 447-462.

Ertmer, P. A., Gopalakrishnan, S., \& Ross, E. (2000). Technology-using teachers: Comparing perceptions of exemplary technology use to best practice. Paper presented at the Annual Meeting of the American Educational Research Association, New Orleans, LA. Retrieved from:

http://www.edci.purdue.edu/ertmer/docs/AERA_2000.pdf

Ertmer, P. A. (2005). Teacher pedagogical beliefs: The final frontier in our quest for technology integration? Educational Technology Research and Development, 53(4), 25-39.

http://dx.doi.org/10.1080/15391523.2010.10782551

Ertmer, P. A., \& Ottenbreit-Leftwich, A. T. (2010). Teacher technology change: How knowledge, confidence, beliefs, and culture intersect. Journal of Research on Technology in Education, 42, 255-284.

Estonian Ministry of Education and Research (2011). National Curriculum. Retrieved from:

https://www.hm.ee/en/activities/pre-school-basic-and-secondary-education

European Commission (2014). The international computer and information literacy study (ICILS): Main findings and implications for education policies in Europe. Retrieved from:

ec.europa.eu/education/library/study/2014/ec-icils_en.pdf

Goodson, I., \& Mangan, J. F. (1995). Subject cultures and the introduction of classroom computers. British Educational Research Journal, 21, 613-629. http://dx.doi.org/10.1080/0141192950210505

Grivins, M. (2012). Implementation of per capita education funding in the Baltic States. Baltic Journal of European Studies, 2, 87-108. http://dx.doi.org/10.11590/bjes.2012.2.05

Hammond, M., Reynolds, L., \& Ingram, J. (2011). How and why do student teachers use ICT? Journal of Computer Assisted Learning, 27, 191-203. http://dx.doi.org/10.1111/j.1365-2729.2010.00389.x

Hasebrink, U., Livingstone, S., Haddon, L., \& Ólafsson, K. (2009). Comparing children's online opportunities and risks across Europe: Cross-national comparisons for EU Kids Online. LSE, London: EU Kids Online. Retrieved from: http://eprints.Ise.ac.uk/21656/

Hennessy, S., Ruthven, K., \& Brindley, S. (2005). Teacher perspectives on integrating ICT into subject teaching: Commitment, constraints, caution and change. Journal of Curriculum Studies, 37, 155-192. http://dx.doi.org/10.1080/0022027032000276961

Inan, F. A., Lowther, D. L., Ross, S. M., \& Strahl, D. (2010). Pattern of classroom activities during students ' use of computers: Relations between instructional strategies and computer applications. Teaching and Teacher Education, 26, 540-546. http://dx.doi.org/10.1016/j.tate.2009.06.017 
John, P. (2005). The sacred and the profane: Subject sub-culture, pedagogical practice and teachers perceptions of the classroom uses of ICT. Educational Review, 57, $471-490$.

http://dx.doi.org/10.1080/00131910500279577

John, P. D., \& Baggott la Velle, L. (2004). Devices and desires: Subject subcultures, pedagogical identity and the challenge of information and communications technology. Technology, Pedagogy and Education, 13, 307-326. http://dx.doi.org/10.1080/14759390400200185

Kagan, D. M. (1992). Implications of research on teacher belief. Educational Psychologist, 27, 65-90. http://dx.doi.org/10.1207/s15326985ep2701_6

Kalmus, V., von Feilitzen, C., \& Siibak, A. (2012). Effectiveness of teachers' and peers' mediation in supporting opportunities and reducing risks online. In S. Livingstone \& L. Haddon (Eds.), Children, risk and safety on the internet: Research and policy challenges in comparative perspective (pp. 245-256). UK: Policy Press.

Kalmus, V. (2013). Making sense of the social mediation of children's internet use: Perspectives for interdisciplinary and cross-cultural research. In C. W. Wijnen, S. Trültzsch, \& C. Ortner (Eds.), Medienwelten im Wandel: Kommunikationswissenschaftliche Positionen, Perspektiven und Konsequenzen. Festschrift für Ingrid Paus-Hasebrink (pp. 137-149). Wien: Springer.

Kangro, A., \& Kangro, I. (2004). Integration of ICT in teacher education and different school subjects in Latvia. Educational Media International, 41(1), 31-37.

Karaseva, A., Pruulmann-Vengerfeldt, P., \& Siibak, A. (2013). Comparison of different subject cultures and pedagogical use of ICTs in Estonian schools. Nordic Journal of Digital Literacy, 3, 157-171.

Kozma, R. (Ed.). (2003). Technology, innovation and educational change: A global perspective. Eugene, OR: Information Society for Technology in Education [ISTE] Publications.

Kozulin, A. (2003). Psychological tools and mediated learning. In A. Kozulin, B. Gindis, V. S. Ageyev, \& S. M. Miller (Eds.), Vygotsky's educational theory in cultural context (pp. 15-38). Cambridge, UK: Cambridge University Press.

Latvian Ministry of Education and Science (2013). Noteikumi par valsts vispārējās vidējās izglītības standartu, mācību priekšmetu standartiem un izglītības programmu paraugiem [Regulation on the state general secondary education standard, subject standards, and educational curriculum]. Retrieved from: http://likumi.Iv/doc.php?id=257229

Lim, C. P., \& Chai, C. S. (2008). Teachers' pedagogical beliefs and their planning and conduct of computer-mediated classroom lessons. British Journal of Educational Technology. 39, 807-828. http://dx.doi.org/10.1111/j.1467-8535.2007.00774.x

Livingstone, S., \& Bober, M. (2004). Taking up opportunities? Children's uses of the internet for education, communication and participation. E-Learning, 1, 395-419.

http://dx.doi.org/10.2304/elea.2004.1.3.5

Livingstone, S., Haddon, L., Görzig, A., \& Ólafsson, K. (2011). Technical report and user guide: The 2010 EU Kids Online survey. London: EU Kids Online.

Livingstone, S., \& Haddon, L. (2012). Theoretical framework for children's internet use. In S. Livingstone \& L. Haddon (Eds.), Children, risk and safety on the internet: Research and policy challenges in comparative perspective (pp. 1-14). UK: Policy Press.

Mägi, E. (2006). Issues in Estonia: The challenge of having fewer children! Thematic dossiers for observatory for the new technologies and education. Retrieved from:

http://insight.eun.org/ww/en/pub/insight/thematic-dossiers/articles

Mendoza, K. (2009). Surveying parental mediation: Connections, challenges, and questions for media literacy. Journal of Media literacy Education, 1, 28-41. 
Niederhauser, D. S., \& Stoddart, T. (2001). Teachers' instructional perspectives and use of educational software. Teaching and Teacher Education, 17(1), 15-31. http://dx.doi.org/10.1016/S0742-

$051 \times(00) 00036-6$

Nikken, J, \& Jansz, J. (2011). Parental mediation of young children 's internet use. EU Kids Online Conference paper.

Pajares, M. F. (1992). Teachers' beliefs and educational research: Cleaning up a messy construct. Review of Educational Research, 62, 307-332. http://dx.doi.org/10.3102/00346543062003307

Palak, D., \& Walls, R. T. (2009). Teachers` beliefs and technology practices: A mixed-methods approach. Journal of Research on Technology in Education, 41, 417-441.

http://dx.doi.org/10.1080/15391523.2009.10782537

Peterson, J. M. (2012). Switching roles: An investigation into the use of reverse mentoring by students to encourage teachers' uptake of ICT in their pedagogical approach. Ph.D. Thesis, University of Curtin, Australia.

Reynolds, D., Treharne, D., \& Tripp, H. (2003). ICT - the hopes and the reality. British Journal of Educational Technology. 34, 151-167. http://dx.doi.org/10.1111/1467-8535.00317

Selwyn, N. (1999). Differences in educational computer use: The influence of subject cultures. Curriculum Journal. 10(1), 29-48. http://dx.doi.org/10.1080/0958517990100104

Strauss, A., \& Corbin, J. (1998). Basics of qualitative research: Grounded theory procedures and techniques. London: Sage.

UNESCO (2011). Media and information literacy curriculum for teachers. Retrieved from: http://unesdoc.unesco.org/images/0019/001929/192971e.pdf

Voogt, J., \& Pelgrum, H. (2005). ICT and curricula change. Human Technology, 1, 157-175.

Warren, R. (2003). Parental mediation of preschool children 's television viewing. Journal of Broadcasting and Electronic Media. 47, 394-417. http://dx.doi.org/10.1207/s15506878jobem4703_5

Watson, D. (2006). Understanding the relationship between ICT and education means exploring innovation and change. Education and Information Technologies, 11, 199-216.

http://dx.doi.org/10.1007/s10639-006-9016-2

Wishart, J. (2004). Internet safety in emerging educational contexts. Computers \& Education, 43, 193204. http://dx.doi.org/10.1016/j.compedu.2003.12.013

Zhao, Y. (2004). Social studies teachers ' perspectives on technology integration. Ph.D. thesis. University of Georgia, USA. Retrieved from:

http://athenaeum.libs.uga.edu/bitstream/handle/10724/7484/zhao_yali_200405_phd.pdf?sequence=1

Zhao, L., Lum, Y., Wang, B., \& Huang, W. (2010). What makes them happy and curious online? An empirical study on high school students ' internet use from a self-determination theory perspective. Computers \& Education, 56, 346-356. http://dx.doi.org/10.1016/j.compedu.2010.08.006

\section{Correspondence to:}

Agnese Karaseva

Institute of Social Studies

University of Tartu

Lossi 36

Tartu, 51003

Estonia

Email: agnese.karaseva(at)gmail.com 


\section{About author(s)}



Agnese Karaseva is a PhD student at the University of Tartu and lecturer at Vidzeme University of Applied Sciences in Latvia. Her dissertation topic is on the digital literacy of secondary school teachers.

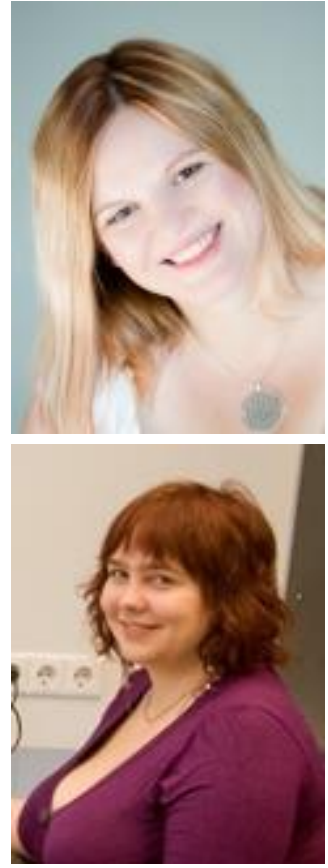

Andra Siibak, PhD, is a Senior Research Fellow of Media Studies in the Institute of Social Sciences at the University of Tartu. Her present research interests deal with new media audiences, generations and intergenerational relations on social media, mediation of children's ICT use and privacy on social media. Her articles have appeared in Journal of Computer Mediated Communication, Cyberpsychology, Northern Lights, Journal of Nordic Digital Literacies, Young, etc.

Pille Pruulmann-Vengerfeldt is a professor in media studies at the University of Tartu, Institute of Social Studies and a part-time researcher at Estonian National Museum. Her interests are related to the internet and social media privacy, internet user typologies, user-friendly online spaces. She is part of the management team for the ERCREA European Media and communication training programme and chair of the Audience and Reception Studies Section of ECREA. Her publications include articles in First Monday, Journal of Baltic Studies, Journal of Computer Mediated Computation and several chapters in edited volumes. 